\title{
La política urbana y el Plan Director de la ciudad de México, ¿proceso operativo o fachada política?*
}

\author{
Adrián Guillermo Aguilar**
}

En este trabajo se exploran las razones que tuvo el Estado mexicano en la década de los setenta para institucionalizar una politica urbana a nivel nacional y local. Se revisan también los objetivos de la Ley General de Asentamientos Humanos y del Plan Nacional de Desarrollo Urbano. En concreto, se examinan los mecanismos especificos que, para cumplir sus objetivos, se incluyeron en el Plan Director de la Ciudad de México 1980-1982. En éste se analizan el control de la expansión física en la zona de amortiguamiento y la participación popular, para ver en qué medida el Estado mostró un real interés por establecer instrumentos operativos efectivos y especificos para cumplir con ios ambiciosos objetivos de la planeación urbana, o hasta qué punto fue esta última sólo un ejercicio retórico que careció de mecanismos de instrumentación.

\section{Introducción}

En la segunda mitad de los años setenta, el estatus político de la planeación fue fortalecido en México a través de distintas instituciones públicas. La planeación se usó como elemento de una aparente modernización del aparato gubernamental, en un momento en que se necesitaban nuevas reformas. La planeación urbana adquirió un papel prominente, y fue vista como un instrumento adecuado para regular el crecimiento urbano del país, como un medio para racionalizar el sistema administrativo y como un canal democrático para incorporar a los ciudadanos en la toma de decisiones a nivel local.

Fundamentalmente, esto contribuyó a elevar las expectativas del ciudadano común acerca de su posible función. La planeación fue asociada con nuevas políticas e instrumentos de desarrollo para el país, en las cuales sería el instrumento "regulador". En este trabajo examino hasta qué punto los pronunciamientos de la planeación en México estuvieron acompañados de mecanismos operativos reales y adecuados para lograr los objetivos propuestos o en qué medida fueron adoptados primordialmente como parte de un ejercicio retórico para recobrar parte del consenso politico perdido por el Estado ante las dificultades económicas y políticas de años anteriores.

La introducción de la planeación en América Latina ha sido un fenómeno relativamente reciente. A pesar de que las actividades de planeación

* Conacyt, ANUIES y el Consejo Británico aportaron apoyo financiero para esta investigación. El autor expresa su agradecimiento a dichas instituciones.

* Investigador del Instituto de Geografia, UNAM. 
se iniciaron en los años cuarenta y cincuenta, fue hasta la década de los sesenta cuando se incrementaron y convirtieron en un rasgo común de la mayoría de los países latinoamericanos (véase Cibotti y otros, 1974: 30-31). La institucionalización de la planeación generalmente significó el establecimiento de numerosas oficinas y la elaboración de distintos tipos de planes. ${ }^{1}$ Pero fundamentalmente la planeación fue vista como un instrumento para mejorar el estado de subdesarrollo de la región y, por tanto, fue asociada con objetivos muy ambiciosos dirigidos a acelerar el desarrollo económico y social (véase ILPES, 1966:7, Riffka y Fernández, 1981:97).

Sin embargo, la planeación no ha implicado siempre la aplicación de los planes. A pesar de que ellos se han elaborado a todos los niveles, rara vez se han hecho operativos. Los países de América Latina han tenido planes pero han carecido de un proceso de planeación efectivo (De Mattos, 1979:81). En otras palabras, se han escrito muchos documentos formales con propuestas de planeación, pero no se han llevado a la práctica. Como Wynia (1972:3) sostiene, la planeación ha sido más decorativa que indicativa. ¿Por qué? El aspecto crucial es que las propuestas de planeación han carecido de apoyo político. Los planes tienden a ser excesivamente ambiciosos en sus pretendidas reformas y por lo tanto no son políticamente viables. La planeación propone generalmente un conjunto de soluciones que amenazan las bases reales del soporte político de los gobiernos nacionales (De Mattos, 1979:80). Soluciones como reformas hacendarías con fines distributivos, reestructuraciones burocráticas o cambios en el sistema de propiedad de la tierra amenazan los intereses de los grupos dominantes. Este tipo de soluciones han representado un costo político muy alto para los gobiernos, que no han ofrecido respuestas rápidas y prácticas para cuellos de botella críticos; por lo tanto, los programas han permanecido en gran medida sin ponerse en práctica (Wynia, 1972:188). Las políticas de planeación urbana han sido elaboradas como parte del proceso de planeación general y han sufrido en gran medida las mismas dificultades que éste; han sido pobremente desarrolladas tanto en términos de su elaboración como de su ejecución. ${ }^{2}$

Un aspecto que debe enfatizarse es que, a pesar de que los planes no se llevan a la práctica, las instituciones de planeación siguen en pie y la elaboración de planes continúa. Esto sugiere que la planeación es hasta cierto punto políticamente útil para el Estado. En primer lugar, se utiliza para negociar ayuda financiera externa (Cibotti y otros, 1974:39). A menu-

\footnotetext{
${ }^{1}$ La proliferación e institucionalización de la planeación en América Latina estuvo intimamente ligada a la creación, en 1961, de la Alianza para el Progreso. Ésta fue un esfuerzo multilateral (ampliamente apoyado por Estados Unidos, en respuesta a la Revolución cubana), para acelerar el desarrollo económico y social de los países latinoamericanos (Baltra, 196\% 215).

${ }^{2}$ La planeación urbana ha sido categorizada también como excesivamente ambiciosa en sus propuestas (véase McAuslan, 1985: capítulo 5), que enfatizan las obras físicas sin considerar los aspectos sociales y económicos (véase Cornelius y Kemper, 1978).
} 
do la elaboración de planes ha tenido el objetivo fundamental de asegurar asistencia económica externa sin considerar la naturaleza intrínseca de los proyectos o su posible realización. $Y$ en segundo lugar, como argumentaré en este trabajo, la planeación corre el riesgo, ante la carencia de procesos operativos específicos, de convertirse en un instrumento ideológico creador de expectativas falsas. Las perspectivas optimistas que ofrece y las amplias expectativas que despierta, pueden servir para apaciguar tensiones sociales en momentos críticos. Bajo estas condiciones, la planeación se convierte en un ejercicio retórico que no cuenta con los mecanismos adecuados para lograr sus objetivos.

\section{La política urbana de los años setenta en México}

A mediados de los años setenta, el primer paso para institucionalizar una pclítica urbana nacional fue dado en México bajo la presidencia de Luis Echeverría (1970-1976). La Ley de Asentamientos Humanos (LAH) representó la principal base de esta política. La administración de José López Portillo (1976-1982) consolidó esta tendencia con el Plan Nacional de Desarrollo Urbano (PNDU), dictado en 1978, con el establecimiento de instituciones de planeación y con la elaboración de numerosos planes para los diversos niveles territoriales. ${ }^{3}$ Sin embargo, la LAH y el PNDU fueron utilizados por el Estado como instrumentos de legitimación, dado que ambos fueron vagos y débiles en sus mecanismos de aplicación.

A principios de su mandato, Echeverría enfrentó una crisis política y económica. ${ }^{4} \mathrm{El}$ modelo de desarrollo utilizado por los diferentes gobiernos de 1940 a 1970 (ampliamente basado en una industrialización sustitutiva de importaciones), falló en elevar el nivel de vida de los grupos más pobres, no creó suficientes empleos para estos grupos, y polarizó los beneficios sociales y económicos. Un amplio sector de los pobres urbanos y los campesinos fueron mantenidos por debajo de o en un nivel de relativa pobreza (Blanco, 1981:300). El inmenso gasto público en infraestructura física llevado a cabo durante los años cuarenta y cincuenta, y el desequilibrio en el balance de pagos, llevaron al Estado a cubrir estos costos con deuda externa e inversión extranjera. El Estado estuvo imposibilitado para expandir su actividad productiva y la inversión privada también decayó (véase González Casanova y Florescano, 1979: 68 y 69). A finales de los años sesenta, estas condiciones tuvieron un gran impacto en el sistema

\footnotetext{
${ }^{3}$ La administración del presidente De la Madrid (1982-1988), continuó con estas políticas a través del Plan Nacional de Desarrollo 1983-1988 y el Programa Nacional de Desarrollo Urbano y Vivienda 1984-1988. Para comentarios y criticas a estos dos planes véase Garza (1986).

${ }^{4}$ Castells [1977: 1187) ha señalado que a fines de los sesenta, la crisis de hegemonía política coexistra con la crisis económica como parte integrante e indisoluble y no como mero componente coyuntural. "La primera provenia, sobre todo, de la inadecuación entre las relaciones de clase que se habian desarrollado en la sociedad civil y aquéllas presentes en el bloque de poder subyacente a la forma del Estado".
} 
político. Los altos niveles de pobreza y la ausencia de canales efectivos de expresión política para democratizar el sistema político nacional, provocaron un creciente descontento y un cuestionamiento de la legitimidad del Estado (Blanco, 1981: 303).

Sin esta crisis económica y política no puede entenderse el enfoque reformista adoptado por el presidente Echeverría. Al principio de su administración era necesaria una "reforma", una nueva estrategia de desarrollo para restablecer el balance. Esta circunstancia llevó a su gobierno a proponer el llamado "desarrollo compartido", haciendo énfasis en el desarrollo regional, en un intento por rectificar el modelo de acumulación y recobrar la legitimidad perdida debido a las acciones represivas del gobierno anterior. Sin embargo, la aplicación de una política regional nunca fue respaldada por los grupos poderosos económicamente (Unikel y Lavell, 1979: 54-56), y el Estado tuvo que recurrir a un grupo de medidas a nivel intraurbano con el fin de aliviar las tensiones sociales y "racionalizar" la dotación de costosa infraestructura. De esta manera, el Estado pasó de las cuestiones regionales a un mayor énfasis en lo urbano, recurriendo a una política urbana integral (con la LAH); consolidó así la nueva estrategia de desarrollo que necesitaba, al promover los nuevos conceptos de planeación como "generadores de cambio" y como un signo de modernización, y alimentó también la retórica ideológica de redistribución de beneficios, por medio de una propuesta corrección de las desigualdades territoriales (véase Aguilar, 1986: capítulo 5). Naturalmente, como sostengo más adelante, estos cambios nunca sucedieron.

La LAH fue una regulación que tuvo un alto contenido demagógico, ya que careció de mecanismos especificos para afectar los intereses del capital financiero e inmobiliario a nivel urbano. Ramírez Sáiz (1983) ha intentado demostrar cómo esta ley se convirtió en un intento pobre y vago para "regular" los problemas urbanos. La ley incluía fines muy optimistas: su artículo 3 establecía que "la planeación y el control de los asentamientos humanos tenderia [ . . .] a usar los elementos naturales (por ejemplo, la tierra) para beneficio social y para distribuir equitativamente la riqueza pública del país" (Diario Oficial, 26-5-76). Esta clase de afirmaciones, con un aparente interés por beneficiar a la mayoría de la población, provocó una fuerte oposición, particularmente de grupos de capital a nivel urbano. Esta oposición llevó al Estado a conceder las modificaciones que se demandaban, y la ley fue aprobada sólo cuando era lo suficientemente general y vaga en sus mecanismos para no poner en riesgo los intereses de los grupos urbanos dominantes. La ley se convirtió en una medida oportunista que el gobierno adoptó para crear una imagen progresista en un medio politico deteriorado, y en un momento cuando existía un gran interés internacional en los asentamientos humanos. ${ }^{5}$

\footnotetext{
${ }^{5}$ En mayo-junio de 19r6, la Conferencia de las Naciones Unidas acerca de los asenta-
} 
Durante el mandato de López Portillo se reforzó la importancia de lo urbano y se formalizó legalmente un sistema de planeación urbana a nivel nacional. Esto implicó básicamente la creación de instituciones para la planeación y de planes para los diversos niveles territoriales. Destaca la creación de la Secretaria de Asentamientos Humanos (SAHOP) en 1976, la de la Comisión Nacional de Desarrollo Urbano en 1977 y la actuación de seis comisiones regionales de áreas conurbadas. La primera comisión se encargó de elaborar el PNDU y los planes de desarrollo urbano para los 32 estados y los 2375 municipios del país. ${ }^{6}$ Deben enfatizarse dos aspectos fundamentales acerca de este firme apoyo público a las actividades de planeación urbana a todos los niveles. Primero, todas las tareas de planeación representaban una empresa de tal magnitud que era dudoso que el aparato gubernamental pudiera cumplir satisfactoriamente con ellas tanto en términos técnicos como ejecutivos (Rébora, 1978: 1189). El enfoque era muy optimista no sólo para la elaboración sino también para la aplicación de los planes. Segundo, las propuestas del PNDU mostraban importantes limitaciones para el desarrollo regional que se intentaba. Específicamente, el énfasis dado a la promoción de centros urbanos, sobre todo a través de una descentralización industrial, respondía en gran medida a una lógica para reforzar un desarrollo industrial con base en áreas urbanas. Esto significaba que el crecimiento económico tendría en el futuro un marco urbano, mientras que los vínculos rural-urbanos y el desarrollo regional integral estaban siendo relegados. De hecho, el mismo patrón de desarrollo espacialmente concentrado que había predominado hasta esa fecha, iba a continuar y, por ende, las desigualdades sociales y económicas asociadas con él. Más aún, el PNDU no especificaba prioridades y acciones a corto plazo, ni los mecanismos para la inversión pública; además de que el número de ciudades con políticas de impulso era excesivo (Rébora, 1978: 1187).

Todo lo anterior sugiere que el Estado estuvo muy interesado en el establecimiento de un sistema de planeación urbana y en la elaboración masiva de planes, pero descuidó su posible puesta en práctica y, por lo tanto, el logro de sus objetivos. ${ }^{7}$ Las instituciones para la planeación y los mis-

mientos humanos (Habitat) tuvo lugar en Vancouver, Canadá. La LAH fue apresuradamente aprobada en mayo de 1976, precisamente justo antes de la Conferencia. Asi, cuando el presidente Echeverría dio su discurso en ésta, pudo mostrar una imagen innovadora.

${ }^{6}$ Una medida legislativa adicional, las Declaratorias de Provisiones, Usos, Reservas y Destinos de Áreas y Predios, también tenia que ser elaborada para todos los estados, municipios y zonas conurbadas, lo cual suma, aproximadamente, 2413 regulaciones de este tipo (Ramírez Sáiz, 1983: 6).

7 Parece que esto es una práctica común dentro de la planeación en otros países de América Latina. Por ejemplo, en su estudio sobre Ecuador, Bromley (1977: 68) señala que un problema crónico de la planeación es la excesiva concentración en la elaboración de instrumentos y la creación de controles burocráticos, y la falta de atención a la puesta en práctica de los planes; véase también De Mattos (1979). 
mos planes tuvieron una gran significancia política para el gobierno como instrumentos de modernización del aparato estatal. Al final del sexenio de Echeverría, la devaluación del peso y un gran aumento de la deuda externa agravaron la crisis económica y surgieron limitaciones políticas reales a la toma de decisiones en el Estado a través del financiamiento. Los planes y programas de inversión se vieron sujetos a múltiples restricciones al depender su realización del capital financiero internacional (González Casanova y Florescano, 1979: 71). La administración de López Portillo estimuló la consolidación de la política urbana nacional, lo que mostraba una cierta continuidad con el modelo de desarrollo capitalista de base urbano-industrial que había predominado hasta esa fecha. Asimismo, el marco de planeación urbana ayudaba a justificar, a nivel territorial, la asignación y magnitud de los recursos financieros de una "manera planeada". Es decir, es posible que los planes estuvieran funcionando más como documentos políticos que como propuestas reales para corregir los problemas intra e interurbanos o como mecanismos para redistribuir los beneficios del desarrollo entre los sectores sociales más pobres. Los objetivos poco realistas de estos planes y la ausencia de procesos específicos para llevarlos a cabo sugieren que con ellos se perseguían sobre todo fines políticos, y no aquellos vinculados a una mayor eficiencia administrativa o a la disminución de las desigualdades regionales.

\section{El Plan Director, 1980-1982}

Como resultado de los diferentes planes elaborados para todos los centros urbanos del país, un plan regulador para la ciudad de México fue aprobado en 1980. El llamado Plan Director (PDDF), representaba el instrumento central de planeación para regular el crecimiento de la ciudad capital. ${ }^{8}$ Como base de su estrategia, proponía una zonificación primaria que dividía al territorio del Distrito Federal en tres grandes zonas: el área urbana, la zona de amoriguamiento y la zona de conservación (véase la figura 1). Este plan para la ciudad capital es el primero que ha estado vinculado a una política urbana nacional y tal vez ha sido el más ambicioso.

En la siguiente sección examino hasta qué punto la planeación urbana fue operativa a nivel local y si sus regulaciones fueron adecuadas para las características que el proceso urbano presenta en la ciudad de México. El análisis de este plan proporciona un buen medio para valorar la efectividad y el impacto del aparato de planeación a nivel local. Para llevar a cabo sus objetivos, el plan incluía 11 programas, cada uno de los cuales

\footnotetext{
${ }^{8}$ Cabe sen̄alar que el Plan Director fue elaborado únicamente para el Distrito Federal, que es la entidad que incluye la mayor parte del área urbana de la ciudad capital. Lo anterior es una de sus principales deficiencias, ya que la parte de la ciudad de México que corresponde al estado de México no fue considerada en este instrumento de planeación urbana.
} 
FIGURA 1

\section{Zonificación propuesta por el Plan Director del Distrito Federal}

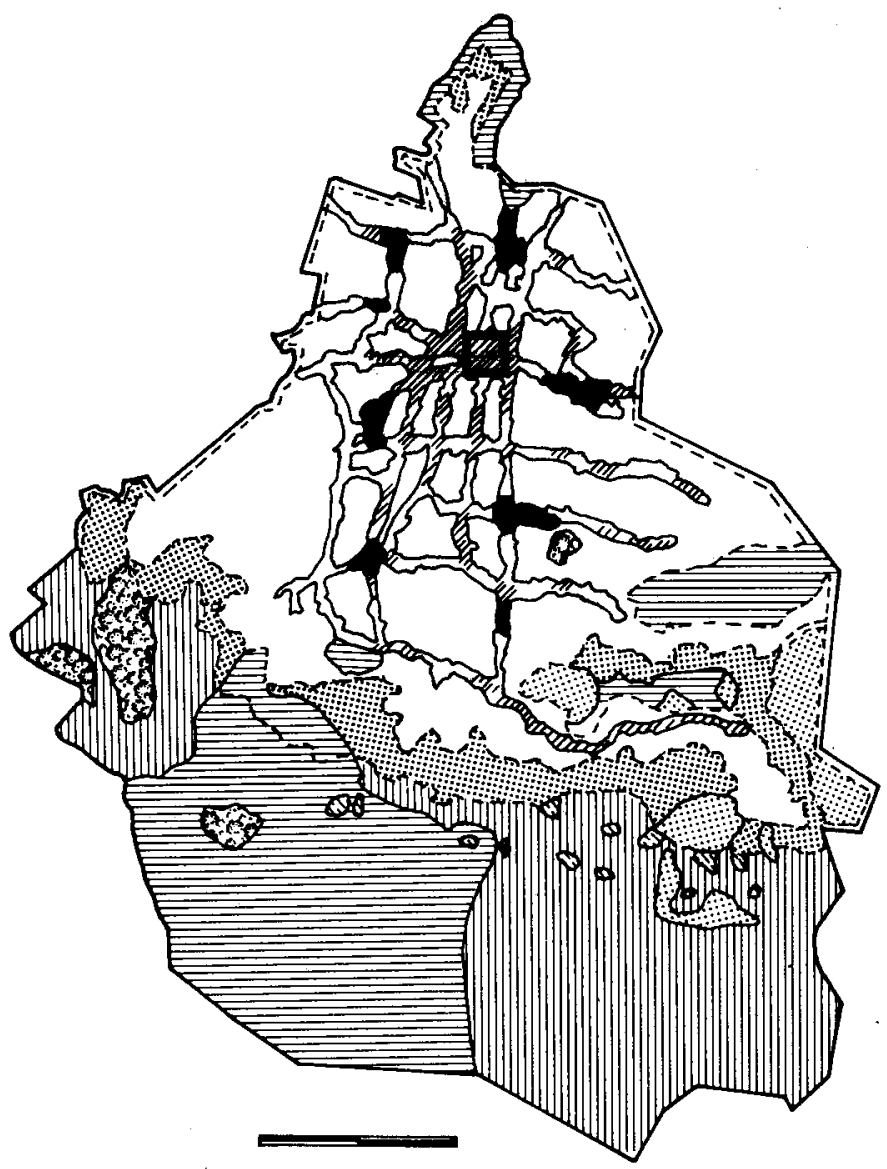

\footnotetext{
_ Limite del Distrito Federal

- _ - Area susceptible de desarrollo urbano

- _. Area a conservar

Centro metropolitano

Centros urbanos

ك Corredores urbanos

Principales usos del suelo

WZZ Servicios, comercio y otros

$\square$ Industria

$\square$ Vivienda
}

Fuente: DDF (1980).

Wona de amortiguamiento

Panque nacional

E Parque metropolitano

Zonas agricolas

IIII Zonas boscosas

ESV Poblados rurales 
correspondia a un elemento particular de la estructura urbana (tierra, vivienda, transporte, centros urbanos, etc.) (véase DDF, 1980: 93). Con el fin de evaluar hasta dónde fueron puestas en práctica algunas de sus principales propuestas, escogi analizar dos aspectos: las normas del uso del suelo para regular la expansión urbana y la participación comunitaria. Mi objetivo es analizar dos aspectos distintos de la aplicación de la planeación urbana en la ciudad de México, para obtener una visión más amplia de la aplicación y efectividad de los programas de planeación. Consideré que el control de la expansión de la ciudad era un punto crítico del PDDF, dada la amplia demanda de vivienda y las ocupaciones ilegales del suelo urbano; por otra parte, el esquema de participación popular era el primero de este tipo que se establecía en el Distrito Federal, por lo que resultaba interesante examinar sus logros y limitaciones. Para tal efecto se presentan los resultados de una encuesta aplicada en 1984 en 369 viviendas en la delegación de Tlalpan, hacia el sur del Distrito Federal. Estos datos fueron usados para evaluar el plan; la encuesta se aplicó, con propósitos comparativos, a asentamientos localizados tanto en el área urbana como en la zona de amortiguamiento de la misma delegación.

\section{El control de la expansión física}

Para examinar las normas del uso del suelo, mi interés se centró básicamente en la llamada zona de amortiguamiento, que representaba un área de transición entre el área urbana y las zonas no urbanizadas en el extremo sur de la ciudad de México. Su principal objetivo era disminuir la expansión física aplicando la zonificación y otras normas de uso del suelo. La efectividad de estas regulaciones surge como algo muy importante si se considera que el proceso urbano en la ciudad de México está en gran medida dominado por la especulación del mercado de la tierra y por medios ilegales en la apropiación del suelo urbano.

La zona de amortiguamiento fue definida en 1980 como una franja que variaba de uno a tres kilómetros de ancho y que cubría un área de 165 $\mathbf{k m}^{2}$ (DDF, 1980: 77). Los controles del uso del suelo que se aplicarian eran de tres tipos: zonificación, normas de ocupación y licencias de construcción. La zonificación secundaria de esta área particular permitía cuatro principales usos del suelo: poblados rurales (ya existentes), cuya expansión sería regulada; agropecuario intensivo; servicios extensivos (principalmente recreacionales y turísticos), y parques. De manera notable, el uso del suelo habitacional no estaba permitido fuera del perimetro de los poblados rurales existentes (DDF, 1980: 77). De esta manera la zona de amortiguamiento estaba designada para tener una mezcla de usos del suelo urbano de baja densidad y espacios abiertos, los cuales podrian aminorar la expansión urbana. Las normas de ocupación, por su parte, es- 
taban orientadas a controlar la ocupación de lotes individuales para hacerla compatible con la zonificación interna. Estas normas especificaban básicamente la densidad y el área de construcción por lote: la máxima densidad autorizada por lote era de 10 habitantes o una familia por hectárea en áreas residenciales y, en el caso del área de construcción, ésta tenía que representar hasta 0.05 veces el área del lote en zonas no residenciales (DDF, 1982: 19).

El cumplimiento práctico de la zonificación y de las normas de ocupación es controlado a través del otorgamiento de la licencia de construcción. Este permiso de ocupación del suelo es otorgado por las oficinas delegacionales del Departamento del Distrito Federal (DDF), que autorizan al poseedor de un predio a construir o modificar una construcción de acuerdo con los usos del suelo permitidos por los controles de planeación (véase Diario Oficial, 14-12-76: artículo 50). Un aspecto fundamental es que únicamente los poseedores legales de una propiedad pueden solicitar la licencia de construcción. En los diversos documentos que son requeridos para obtener este permiso, la condición legal de la propiedad tiene que ser demostrada. Por lo tanto, la población que obtuvo un pedazo de tierra por medios informales (que representan un gran porcentaje en la ciudad de México), nunca estará en posibilidad de obtener esta licencia.

En un sentido amplio, la principal deficiencia de las normas de ocupación del suelo del PDDF fue la ausencia de controles del mercado de la tierra. A pesar de que las regulaciones de planeación incluyeron declaraciones en el sentido de que se iban a realizar cambios importantes en el mercado del suelo, éstos nunca se hicieron operativos. La Ley de Desarrollo Urbano del Distrito Federal incluye vagas referencias a esta cuestión; su artículo 3 señala que la ley busca "evitar la especulación excesiva de los terrenos y de los inmuebles dedicados a la vivienda popular", mientras que su artículo 9 afirma, aunque de manera muy blanda que "El derecho de propiedad, el de posesión o cualquier otro derecho derivado de la tenencia de predios, serán ejercidos de conformidad con las limitaciones y modalidades previstas en la presente ley. . ." (Diario Oficial, 7-1-76), las cuales nunca se especifican. Por otra parte, el PDDF, en su Programa de Suelo y Reservas Territoriales, incluía la buena intención de "aumentar la participación del sector público en la oferta del mercado del suelo hasta alcanzar un 50\% en 1988" (DDF, 1980: 103). Sin embargo, aparte de estos vagos e ideológicos pronunciamientos, ni la ley ni el plan especificaron nunca los mecanismos para regular el mercado del suelo urbano. Dicho de otra manera, la planeación no proporcionó a los sectores de bajos ingresos opciones reales para la apropiación de su propio pedazo de tierra ni incrementó sus oportunidades de tener acceso a una vivienda.

La ausencia de controles en el mercado de la tierra es importante por dos razones: por el rápido crecimiento urbano de la ciudad, especialmente hacia el sur, y por la proliferación en la apropiación ilegal de la tierra. 
La tendencia de la ciudad a extenderse hacia el sur es particularmente importante porque la zona de amortiguamiento fue creada casi exclusivamente para controlar el crecimiento físico del área urbana en esa dirección. ${ }^{9}$ En el periodo $1970-1980$, la tasa de crecimiento anual de delegaciones al sur, tales como Cuajimalpa, Magdalena Contreras, Tlalpan y Xochimilco, estuvo por arriba de $5.5 \%$, mientras que la de todo el Distrito Federal fue únicamente de $2.4 \%$. Algunas de estas delegaciones (por ejemplo Cuajimalpa y Tlalpan), mantuvieron un crecimiento impresionante, con porcentajes por arriba de $140 \%$ en esa década, mientras que el porcentaje de crecimiento del Distrito Federal fue en ese periodo menor a $44 \%$. La demanda por tierra ha estimulado una mayor especulación del suelo y han surgido muchos asentamientos ilegales. Se estima que los asentamientos con diversos grados de irregularidad en la tenencia de la tierra cubren aproximadamente $40 \%$ del área metropolitana, incluyendo invasiones y fraccionamientos clandestinos (Garza y Schteingart, 1978: 76).

Para evaluar la efectividad en el control de la expansión física, escogí como área de estudio la fracción del área de amortiguamiento correspondiente a Tlalpan. Aparte de haber sido una de las delegaciones con más alto crecimiento demográfico en la década de los setenta, Tlalpan se ha caracterizado también por conflictos en la ocupación del suelo, especialmente desde la apertura de la carretera Picacho-Ajusco en 1976 (véase la figura 2).

\section{Expansión urbana hacia el área de amortiguamiento}

Un análisis detallado de la expansión urbana hacia la zona de amortiguamiento de Tlalpan (ZAT) en el periodo 1980-1984, reveló el surgimiento de un amplio número de áreas construidas recientemente para fines residenciales. El área total de estas construcciones resultó de 312.76 hectáreas, lo cual representó una considerable expansión urbana, si se toma en cuenta el control que supuestamente iba a ser aplicado. ${ }^{10}$ Esta superficie constituye $2 \%$ de la extensión total del área de amortiguamiento en 1980, 165 $\mathrm{km}^{2}$. La expansión física ocurrió fundamentalmente a lo largo de dos ejes básicos: la carretera federal México-Cuernavaca y la carretera PicachoAjusco. En esta última, la ocupación residencial tuvo el mayor impacto, 221 hectáreas, casi tres cuartas partes de toda la expansión (véase la figura 3).

El aspecto fundamental de esta expansión es que no tuvo lugar de acuerdo con las normas de planeación. Los desarrollos residenciales no

${ }^{9}$ Una pequeña zona de amortiguamiento fue también establecida en la Sierra de Guadalupe, en la delegación Gustavo A. Madero, con el mismo fin.

${ }^{10}$ La magnitud de la expansión urbana dentro de la zona de amortiguamiento correspondiente a la delegación de Tlalpan fue obtenida a partir del análisis de fotografías aéreas de entre 1979 y 1984, y de trabajo directo sobre el terreno. 
FIGURA 2

Localización de la zona de amortiguamiento de Tlalpan

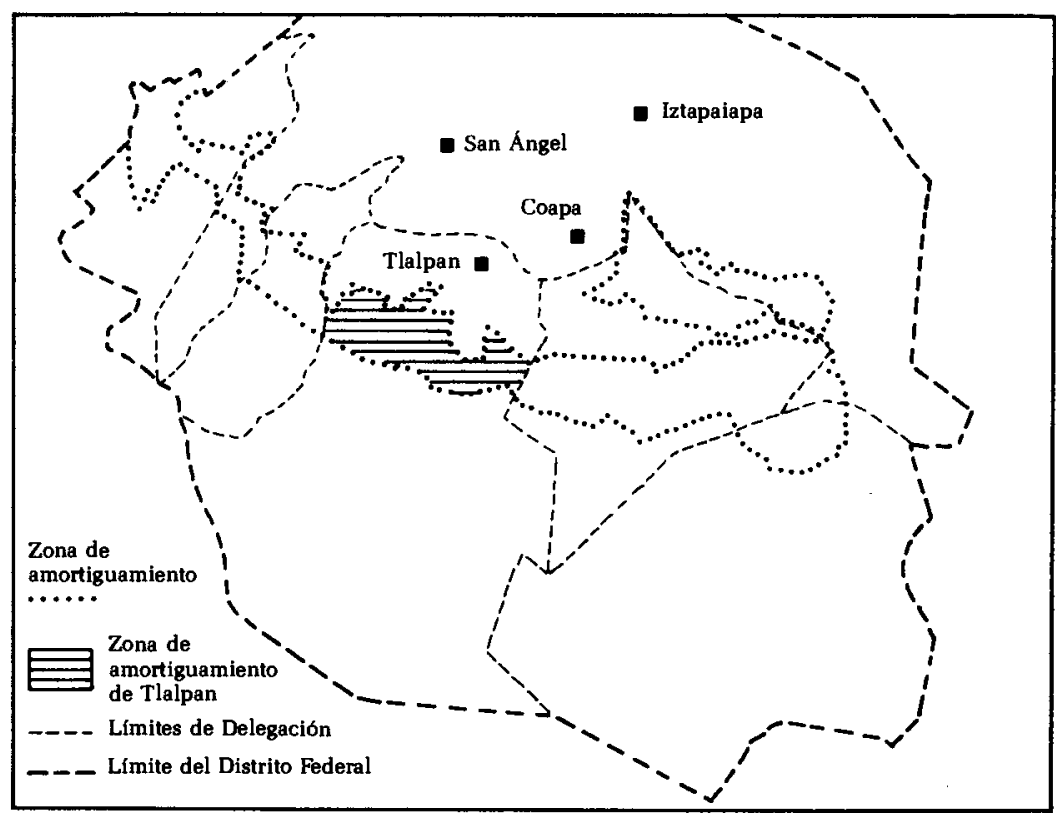

Fuente: DDF (1982).

cumplieron en lo absoluto con las normas de ocupación del suelo. A pesar de que éstas permitían patrones de ocupación con lotes de una hectárea, el cuadro 1 indica que los nuevos desarrollos tuvieron lotes mucho más pequeños con tamaños que variaban entre 240 y 315 metros cuadrados para grupos con ingresos bajos y medios, y lotes promedio de 3706 $\mathrm{m}^{2}$ para sectores de altos ingresos, ambos muy por debajo de la norma. El mismo cuadro 1 muestra que $77 \%$ del área construida recientemente se encuentra asociada a grupos con ingresos bajos y medios (y por lo tanto a lotes pequeños), lo que sugiere que esta expansión urbana hacia la ZAT con respecto al tamaño del lote tuvo lugar de una manera similar a la que ocurre en la mayor parte del área urbana. Diferentes grupos de ingreso se asentaron en la ZAT de distintas maneras: los sectores de bajos ingresos están asociados a desarrollos residenciales a lo largo de la carretera PicachoAjusco, mientras que las clases altas tienden a ocupar el suelo a lo largo de la México-Cuernavaca. 
CUADRO 1

Tamaño de lote y área construida por grupo de ingreso en desarrollos residenciales recientes en el área de amortiguamiento de Tlalpan (1980-1984)

\begin{tabular}{|c|c|c|c|}
\hline $\begin{array}{l}\text { Ingreso familiar* } \\
\text { (media) }\end{array}$ & $\begin{array}{c}\% \text { de área } \\
\text { construida } \\
\text { con respecto } \\
\text { a la expansión } \\
\text { urbana total }\end{array}$ & $\begin{array}{l}\text { Tamaño de } \\
\text { lote en } \mathrm{m}^{2} \\
\text { (media) }\end{array}$ & $\begin{array}{c}\% \text { de área } \\
\text { construida } \\
\text { con respecto } \\
\text { a tamaño } \\
\text { de lote }\end{array}$ \\
\hline Muy bajo & 29.3 & 274.1 & 24.3 \\
\hline Bajo & 32.6 & 313.3 & 22.2 \\
\hline Medio & 15.4 & 241.8 & 28.5 \\
\hline Alto & 22.7 & 3706.2 & 4.4 \\
\hline Total & 100.0 & 1133.8 & 8.1 \\
\hline $\begin{array}{l}\text { * Muy bajo: he } \\
\text { Bajo: de } 36721 \text { a } 48 \\
\text { Medio: de } 48961 \text { a } \\
\text { Alto: } 122401 \text { pesos } \\
\text { El salario mínimo d } \\
\text { Fuente: encues }\end{array}$ & $\begin{array}{l}20 \text { pesos. } \\
\text { sos. } \\
\text { pesos. } \\
\text { esa fecha era de } 8 \\
\text { económica. }\end{array}$ & & \\
\hline
\end{tabular}

Los resultados de la encuesta aplicada a la ZAT muestran que, en los desarrollos residenciales recientes, el área construida por lote representaba generalmente $22 \%$ o más del tamaño del lote, lo cual estaba muy por arriba de $5 \%$ que la norma permitía (cuadro 1). Sólo los grupos de ingresos altos tenían áreas construidas que estaban dentro del límite de la norma (4.4\%); sin embargo, como se señaló, los lotes de estos sectores sociales eran más pequeños que los establecidos en las regulaciones. Aun así, las clases altas son los únicos sectores que muestran una tendencia a cumplir las normas inherentes al concepto de zona de amortiguamiento, pero su proporción sólo representa una quinta parte de toda la expansión urbana que surgió en la ZAT en el periodo 1980-1984.

Por lo tanto, el hecho fundamental es que, ante la ausencia de controles en el mercado de la tierra, ésta estuvo disponible a precios relativamente más baratos que en áreas centrales de la ciudad, un hecho que indujo la ocupación residencial. En la ZAT, diferentes grupos sociales buscaron tierra disponible, que pudieron adquirir principalmente a través de dos medios: por una transacción legal o por una apropiación ilegal.

Transacciones legales de tierra. El análisis de una muestra de transacciones de tierra en la ZAT entre 1979 y 1984, indica que fueron principalmente clases medias y en menor proporción clases altas y capital inmobiliario, los que se apropiaron de amplias fracciones de suelo en esta área. ${ }^{11}$ Esto confirma que la ZAT ha estado recientemente sujeta, por parte

\footnotetext{
${ }^{11}$ Esta muestra acerca de transacciones de tierra se obtuvo del Registro Público de la
} 
de estos intereses económicos, a una alta presión para la compra de tierra, lo cual se explica porque, como han señalado otros estudios, entre las clases medias y altas existe una gran demanda por suelo de propiedad privada, que es cada vez más escaso en el área urbana. A su vez, el mercado de la vivienda para estos sectores también se ha deteriorado debido al aumento en el costo de los materiales de construcción, el aumento en las tasas de interés hipotecario y la caída en los niveles de vida (véase Schteingart, 1983: 294 y 1984: 746).

En el cuadro 2 se muestran las principales características de las transacciones de tierra en la ZAT. De un total de 228 transacciones registradas en la zona, nueve de cada diez se relacionaron con lotes más pequeños de una hectárea, siendo el lote promedio de alrededor de $2000 \mathrm{~m}^{2}{ }^{12} \mathrm{~A}$ pesar de que sólo $10 \%$ se vincula a propiedades mayores de una hectárea, la superficie total involucrada en estas transacciones es mucho mayor que la relacionada con lotes más pequeños. La superficie promedio de tres hectáreas, de todas aquellas transacciones dełlotes mayores de una hectárea, sugiere la coexistencia de algunas grandes propiedades con muchas de tamaño medio. Pero sobre todo, el patrón de propiedad que surge es uno de propiedades de dimensiones medianas, alrededor de $2000 \mathrm{~m}^{2}$, el cual es muy diferente del buscado a través de las normas de planeación, las cuales pretendían inducir propiedades de más de una hectárea.

Apropiación ilegal de la tierra. Como se mencionó, en la ciudad de México una considerable proporción de tierra es adquirida por medios ilegales. Esto está principalmente vinculado a los grupos de bajos ingresos, que tienen que recurrir a estos mecanismos informales para tener acceso a un pedazo de tierra, ya que sus posibilidades de adquirir tierra o vivienda de alto costo dentro del mercado formal son mínimas. ${ }^{13}$ En la ciudad de México hay tres métodos informales ampliamente reconocidos para obtener tierra: los fraccionamientos clandestinos, las invasiones y la venta de tierra ejidal (véase Gilbert y Ward, 1985). El ejido es por ley inalienable; de aquí que su venta para fines urbanos sea ilegal.

En la ZAT se desarrollaron fraccionamientos clandestinos y zonas urbano-ejidales. Como el cuadro 3 lo demuestra, los métodos ilegales de apropiación de tierra por grupos de bajos ingresos representó $74 \%$ del área construida total que surgió en la ZAT en el periodo 1980-1984; de esta

Propiedad (DDF). Las transacciones involucran sólo propiedad privada, en su mayor parte localizada a lo largo de la carretera federal México-Cuernavaca. Esta tierra perteneció en parte a dos antiguas haciendas, las de Xoco y El Arenal, y en parte rodea los poblados rurales de San Miguel Xicalco y Magdalena Petlacalco.

${ }^{12}$ El total de transacciones incluyen principalmente cuatro tipos: compra directa, registro de contratos de compra-venta, prescripción positiva y subdivisión; véase Aguilar (1986: 276280).

${ }^{13}$ Es importante señalar que grupos de clase media también pueden participar en compras ilegales de tierra; véase por ejemplo Varley (1985). 
CUADRO 2

Transacciones de tierra registradas en el periodo 1979-1984 en la zona de amortiguamiento de Tlalpan

\begin{tabular}{lccc}
\hline Tamaño de lote & $\begin{array}{c}\text { Número de } \\
\text { transacciones }\end{array}$ & $\begin{array}{c}\text { Área promedio } \\
\text { de lote en } \mathrm{m}^{2}\end{array}$ & $\begin{array}{c}\text { Área total } \\
\text { acumulada de lotes } \\
\text { en hectáreas }\end{array}$ \\
\hline Menor de una hectárea & 206 & 1961 & 40.40 \\
Mayor a una hectárea & 22 & 32632 & 71.80 \\
\hline Total & 228 & & 112.20 \\
\hline
\end{tabular}

Fuente: cálculos a partir de datos acerca de transacciones de tierra registradas en el Registro Público de la Propiedad, DDF.

expansión urbana, $62 \%$ agrupaba subdivisiones ilegales. En lo que toca al tamaño promedio de lote en estos desarrollos residenciales, las ocupaciones fueron naturalmente más pequeñas, comparadas con las obtenidas por la clase media. El cuadro 3 muestra que el tamaño promedio de lote en subdivisiones ilegales es de $243 \mathrm{~m}^{2}$; en la zona urbano-ejidal es mayor $\left(435 \mathrm{~m}^{2}\right)$, mientras que en la zona producto de una reubicación se presentaron los lotes más chicos $\left(125 \mathrm{~m}^{2}\right)$. Estos procesos informales de apropiación de tierra estuvieron en su mayoría asociados con la carretera Picacho-Ajusco, ya que todos los asentamientos, con excepción de uno, se desarrollaron vinculados a este principal acceso. ${ }^{14}$

De esta manera, los medios ilegales de ocupación del suelo representaron los más importantes métodos que se emplearon para la expansión urbana en la ZAT. Esta expansión estuvo estrechamente ligada a grupos de bajos ingresos que, a través de fraccionamientos clandestinos, zonas urbano-ejidales y una reubicación, tomaron posesión física de la tierra en una zona donde las normas de zonificación no permiten esta clase de asentamientos de lotes relativamente chicos y con densidades medias.

El acatamiento de los controles del uso del suelo. Ante lo expuesto anteriormente la pregunta que surge es ¿qué pasó entonces con la aplicación de los controles del uso de la tierra? Los datos presentados indican que las normas de planeación no funcionaron, probaron ser inadecuadas y fueron ampliamente irrelevantes para prevenir la apropiación del suelo y la construcción de vivienda.

En primer lugar, no existieron controles en el mercado del suelo para

\footnotetext{
${ }^{14}$ A través de entrevistas personales, algunas autoridades del DDF (de la administración 1982-1988), así como líderes locales, coincidieron en afirmar que las autoridades locales del sexenio 1976-1982 fueron tolerantes con esta ocupación y que incluso en algunos casos mostraron cierta complicidad con los fraccionadores ilegales. La escala de la ocupación ilegal fue tal que era prácticamente imposible para las autoridades de la delegación de Tlalpan no darse cuenta de ella.
} 
restringir la disponibilidad de tierra en la ZAT, ni para dar un pedazo de tierra a los grupos más empobrecidos en algún otro lugar de la ciudad, ni para favorecer un patrón de propiedad de lotes grandes en la zona de amortiguamiento. No se puede decir que estos controles fallaran; simplemente no existieron.

En segundo lugar, la planeación no tuvo mecanismos especificos para darle algún tratamiento a los procesos informales de apropiación del suelo a pesar de su amplia recurrencia. De hecho, estos procesos no son ni siquiera mencionados en las regulaciones de planeación ni en las normas. Más aún, el Estado mostró una gran tolerancia hacia dicha ilegalidad, tanto en el proceso de ocupación del suelo como después de él, al permitir la consolidación de los asentamientos sin aplicar ningún control sistemático. La permanencia de los asentamientos confirma lo anterior. En esencia, estos procesos ilegales son el producto de un problema estructural más amplio: la existencia de numerosos sectores empobrecidos sin acceso a tierra y vivienda, para los cuales la planeación no ofrece ninguna posible solución.

CUADRO 3

Formas ilegales de apropiación de tierra en la zona de amortiguamiento de Tlalpan

\begin{tabular}{|c|c|c|c|c|}
\hline Formas & $\begin{array}{c}\text { Área total } \\
\text { construida (ha) }\end{array}$ & $\begin{array}{c}\% \text { con } \\
\text { respecto } \\
\text { al total } \\
\text { de área } \\
\text { construida }\end{array}$ & $\begin{array}{c}\text { Tamaño } \\
\text { de lote } \\
\text { promedio }\left(\mathrm{m}^{2}\right)\end{array}$ & $\begin{array}{c}\text { Ingreso } \\
\text { familiar } \\
\text { (media) }\end{array}$ \\
\hline Subdivisiones ilegales ${ }^{1}$ & 195.11 & 62.3 & 243.0 & Bajo \\
\hline Zonas urbano-ejidales ${ }^{2}$ & 35.49 & 11.3 & 435.2 & Muy bajo \\
\hline Reubicación ${ }^{3}$ & 1.75 & 0.6 & 125.0 & Muy bajo \\
\hline Total & 232.35 & 74.3 & 268.0 & \\
\hline
\end{tabular}

* El área total construida se refiere a la que surgió en el periodo 1980-1984 y que representa un total de 312.76 ha.

${ }^{1}$ Incluye Los Encinos, Tlamille, Lomas Hidalgo, José López Portillo, Cuchilla de Padierna, 2 de Octubre y Belvedere.

${ }^{2}$ Incluye Cuchilla de San Andrés y Ejido San Andrés Totoltepec.

${ }^{3}$ Se refiere a Ampliación Tepechimilpa.

Fuente: encuesta socioeconómica y análisis de fotografias aéreas.

Así, a fin de cuentas y en términos prácticos, el único control que quedaba para aplicar en las normas de uso de suelo era la licencia de construcción. Sin embargo, un análisis detallado de todas las licencias de construcción de la delegación de Tlalpan en el periodo 1979-1983 muestra que, de un total de 2778 licencias, únicamente nueve fueron aprobadas en 
la ZAT. ${ }^{15}$ Estas licencias amparaban una superficie para ser construida de $3080 \mathrm{~m}^{2}$, la cual difícilmente representa una expansión urbana significativa dentro de la zona. Por lo tanto, esta evidencia claramente indica que la gran mayoría de la gente que construyó en el periodo bajo estudio, no obtuvo dicha licencia antes de edificar sus viviendas; de esta manera, la mayoría de las construcciones fueron hechas sin ser registradas ni supervisadas. Una evidencia adicional obtenida de la encuesta aplicada a la población local, corrobora esto. Únicamente $4 \%$ de la gente entrevistada obtuvo una licencia para edificar una vivienda; esto apoya el argumento de que la obtención de esta licencia fue ampliamente irrelevante para construir en la ZAT, tanto para clases medias como para grupos de bajos ingresos. A'quí es importante enfatizar que esta situación no es diferente a lo que pasa en otras áreas de la ciudad de México. En 1981 el director de la Dirección de Planeación (DDF) reconoció que al menos una tercera parte de todas las construcciones en la ciudad capital, en ese tiempo, carecían de permisos de construcción (UnomásUno, 8-9-81).

La falta de estos permisos en la zona de amortiguamiento es del todo sorprendente. Si tres cuartas partes de la tierra local habian sido apropiadas ilegalmente, era entonces lógico suponer que la gente había tratado de obtener una licencia, sin conseguirla, al carecer de todos los documentos legales de posesión. Respondiendo a la pregunta de por qué no se había obtenido un permiso de construcción, la mayoría de los entrevistados argumentó que su situación ilegal habla sido la principal razón; $34 \%$ respondió que carecían de los documentos legales de tenencia de tierra, y que su colonia no estaba oficialmente registrada en la delegación de Tlalpan; otro $20 \%$ respondió que la organización o los líderes locales habían obtenido un permiso oral (sic) de la delegación. Las implicaciones de esto último son muy importantes; se sugiere que los líderes o los fraccionadores involucrados en las apropiaciones ilegales llegaron a un "arreglo" con autoridades locales o con los supervisores de construcciones para desarrollar los asentamientos. Esta tolerancia de las autoridades fue reiterada cuando $15 \%$ de los pobladores mencionó que para construir tuvieron que dar una "gratificación" a los supervisores de construcción o a la policía montada que patrullaba el área, situación que sucedía periódicamente hasta el término de la construcción. Esto confirma la complicidad, mencionada en la anterior sección, que aparentemente existió entre algunas autoridades de la delegación de Tlalpan y los actores principales de las subdivisiones ilegales, y además esto cuestiona la validez de las licencias de construcción como un mecanismo adecuado de control del uso del suelo. Los permisos fueron irrelevantes y confirman la tolerancia del Esta-

${ }^{15}$ Los registros de estas licencias fueron obtenidos de la Oficina de Planeación Urbana de la delegación de Tlalpan. Las listas revisadas se refieren al total de licencias de construcción otorgadas en toda la delegación. 
do hacia ocupaciones y construcciones ilegales.

De lo anterior surge una importante contradicción de la planeación urbana en México. A la vez que el Estado surge como la entidad reguladora del crecimiento urbano a través de una serie de normas de planeación para la ocupación del suelo, al mismo tiempo el aparato estatal es tolerante con la ocupación ilegal del suelo, e incluso en algunos casos favorece dichas acciones.

\section{La institucionalización de la participación comunal 3}

Durante los años setenta se establecieron en el Distrito Federal nuevos mecanismos de participación comunal. Los primeros, recogidos en la Ley Orgánica de 1970 (DDF), fueron ampliados con la ley de 1978 durante la administración de López Portillo (véase Diario Oficial, 29-12-70 y 29-12-78). Los canales de participación popular fueron ampliados en 1978 a cuatro niveles jerárquicos: los residentes locales debían elegir jefes de manzana, quienes serían incorporados en las asociaciones de residentes; el presidente de esta última serviría en la junta de vecinos, existiendo 16 de ellas (una por cada delegación) formadas por un mínimo de 20 residentes locales; finalmente, el presidente de cada junta de vecinos participaría en el Consejo Consultivo del Distrito Federal. En términos generales, estos instrumentos de participación popular, eran únicamente "órganos de colaboración ciudadana", y sus miembros electos durarían tres años en sus puestos.

Un aspecto importante es que este esquema fue el primero creado en la ciudad para canalizar directamente la participación popular en la administración de la ciudad y sus problemas. A pesar de que el Consejo Consultivo del Distrito Federal existía ya antes de 1970, representaba sólo los diversos intereses de asociaciones o grupos de capital legalmente constituidos (Aguilar, 1986: capítulo 4). Sin embargo, los mecanismos de participación comunal presentan en el periodo 1978-1982 una estructuración débil y limitan a las masas el grado de acceso al proceso de toma de decisiones. ${ }^{16}$

Los dos principales objetivos del Programa de Participación Popular del PDDF eran "procurar una responsabilidad conjunta entre los ciudadanos y el DDF en la formulación de las decisiones relacionadas con el desarrollo urbano", y fortalecer la organización ciudadana (DDF, 1980: 37). En otras palabras, el interés estaba centrado en estimular a los ciudadanos a participar en los nuevos mecanismos y aumentar el número de jefes de manzana y en consecuencia el número de individuos involucrados. Todas

\footnotetext{
${ }^{16}$ Ward (1981) ha indicado que en su primer periodo 1970-1976, este esquema de participación popular no funcionó en lo absoluto, ya que las relaciones cliente-patrón dominaban el cumplimiento de demandas populares en el gobierno de la capital.
} 
las demandas locales en cuanto al mejoramiento de las colonias tendrían que ser canalizadas a través de estos comités de manzana. Por lo tanto, es importante saber hasta qué punto la gente participaba en la toma de decisiones y en qué grado los ciudadanos se relacionaron al aparato de planeación en términos de conocimiento acerca de las regulaciones de planeación y participación en los mecanismos creados.

Consulta contra participación. Desde su institucionalización a finales de los años setenta, la participación comunal en la ciudad de México fue sólo como una actividad de consulta que no otorgaba ningún poder ejecutivo a la gente. En sentido estricto, la posibilidad de influir en la dotación de servicios o en la elaboración de planes fue suprimida, y el único derecho concedido al público fue el de ofrecer su opinión. La Ley Orgánica de 1978 definió las responsabilidades de los órganos de participación popular, y claramente señala que las juntas de vecinos y el Consejo Consultivo, nada más pueden "proponer", "informar" o "dar opinión" acerca de importantes aspectos tales como el mejoramiento en la prestación de servicios, las posibles soluciones sobre los servicios educativos, medidas administrativas, problemas de vivienda y proyectos de leyes o reglamentos, así como estudios de planeación urbana (artículos 47 y 51). De esta manera, a la población no le fue otorgado ningún papel activo en el proceso de toma de decisiones; por el contrario, únicamente se le concedió el derecho a ser oída. Aún así, las autoridades del DDF se reservaban el derecho a considerar o no sus opiniones o propuestas. Más aún, los aspectos sobre los cuales se podía opinar fueron impuestos por el gobierno local: no cualquier aspecto social, económico o político era toṕico de propuesta u opinión del público, sino sólo aquéllos especificados en la regulación correspondiente. Las materias para la "participación" no fueron seleccionadas por el público sino impuestas desde arriba.

Un buen ejemplo de cómo la participación ciudadana fue prácticamente bloqueada es el caso del referéndum, que se estableció como una forma directa de participación popular. ${ }^{17} \mathrm{El}$ referéndum tiene por objeto aprobar o rechazar la elaboración, modificación o abrogación de ordenamientos legales o reglamentos relativos al Distrito Federal (artículo 57). Es un importante método de integración directa de la voluntad de los ciudadanos para expresar su opinión acerca de las regulaciones urbanas que los pudieran afectar. Sin embargo, las condiciones que se asocian con su ejecución lo convierten en un medio inefectivo de participación. El referéndum puede ser iniciado exclusivamente por el presidente o las cámaras de diputados o senadores; es obligatorio sólo cuando las regulaciones en cuestión pudieran afectar a la totalidad de los habitantes del Distrito Fede-

\footnotetext{
${ }^{17}$ Además del referéndum, se estableció otra forma directa de participación, que fue la iniciativa popular; ésta es un método para proponer la formación, modificación o derogación de ordenamientos legales, y reglamentos relativos al Distrito Federal (véase Aguilar, 1986: capítulo 7; Ramírez Sáiz, 1983; Císneros Sosa, 1983).
} 
ral y correspondan a la satisfacción de necesidades sociales de carácter general (Diario Oficial, 29-12-78: artículo 58). No se aplica en aspectos de finanzas públicas o materias fiscales. Esto indica que el derecho a promover un referéndum no le fue dado a la gente; es una decisión de representantes gubernamentales de alto nivel, quienes adoptan una posición paternalista que supone que el aparato estatal sabría "el momento preciso" para introducir tal medida. Más aún, la decisión de cuándo una regulación específica podría afectar a todos, o sólo a una sección de los ciudadanos, es tomada por las autoridades en cuestión, excluyendo así el punto de vista de las clases populares. Generalmente es difícil que una legislación afecte por igual a los diferentes grupos sociales; si por ejemplo en un momento específico el Estado local tiende a favorecer a sectores sociales particulares a través de acciones de planeación, podría oficialmente argumentarse que, dado que otros grupos no son afectados, no existe justificación para un referéndum. También es importante hacer notar que los aspectos fiscales y financieros fueron excluidos de las materias elegibles para referéndum; es claro que estos aspectos pueden interesar a sectores más amplios de la población y por lo tanto ofrecen una amenaza potencial para unir a grupos sociales. Así, el Estado, no la sociedad civil, impone lo que puede o no ser materia para un referéndum.

Por lo anterior, tal vez no es sorprendente que durante la administración de López Portillo no hubo un solo caso de referéndum. Por lo mismo, Cisneros Sosa (1983:95) y Ramírez Sáiz (1983: 120) coinciden en señalar que la mayoría de las iniciativas para la participación ciudadana buscan más limitar el rango de participación que ampliar los canales democráticos para las demandas de los habitantes. Los que potencialmente pudieron haber sido valiosos instrumentos de participación, fueron por el contrario moldeados desde arriba y las reglas, lejos de ser un resultado popular, fueron impuestas por las legislaciones gubernamentales.

El conocimiento de los ciudadanos acerca de la planeación. Con el fin de estimular una significativa participación en el esquema de participación comunal era necesario incrementar el conocimiento del público acerca del contenido de las regulaciones de planeación. Uno de los principales objetivos del esquema era divulgar a nivel ciudad y delegación las propuestas de desarrollo comprendidas en los correspondientes planes; lo cual se iba a realizar con una campaña de publicidad permanente a través de mensajes que fueran accesibles a los diferentes grupos sociales (DDF, 1980: 137). Sin embargo, ni los medios de comunicación ni los modos de información que se iban a usar para esta difusión fueron especificados.

De acuerdo con los resultados de la encuesta, la mayoría de la gente no supo nada acerca del PDDF. De los habitantes entrevistados, $64 \%$ contestó que no conocían que existiera ningún plan director para la ciudad. Cuando se hizo la distinción entre ciudadanos del área urbana y de la zo- 
na de amortiguamiento, la respuesta fue más o menos la misma; el cuadro 4 muestra que $55 \%$ en la primera zona y $67 \%$ en la segunda no tuvieron conocimiento acerca del PDDF. Esto indica que en el área urbana sólo alrededor de la mitad de la gente supo acerca del plan, mientras que en el área de amortiguamiento sólo una tercera parte estuvo consciente de él. Sin embargo, cuando este conocimiento fue relacionado con grupos de ingreso surgió una relación peculiar. En los grupos de ingreso más bajo poco menos de un cuarto de la gente supo acerca del plan; en contraste, más de $50 \%$ de los individuos en los dos grupos de ingreso más alto estaban informados acerca del PDDF (véase el cuadro 4). Esto sugiere que el conocimiento del plan está más claramente asociado con ingreso que con localización en la ciudad.

Así, la mayoría de las personas no tuvieron conocimiento de la existencia del PDDF, y esto fue particularmente más notorio para los grupos más pobres, que resultaron ser los menos informados. Esto es especialmente significativo si consideramos que los estratos pobres representan una mayoría en la ciudad, y son normalmente los principales actores de las ocupaciones ilegales de tierra. El gobierno de la ciudad falló en informar adecuadamente a la mayoría de la población local, por lo menos en este caso, acerca de la existencia y objetivos del PDDF.

Cuando se preguntó a los habitantes de la zona de amortiguamiento acerca de la existencia y objetivo de esta zona, la falta de conocimiento de esta norma de planeación fue dramática: $92 \%$ de los individuos entrevistados, que viven dentro de sus límites, no supieron acerca del establecimiento de esta zona, y de los pocos que supieron, casi todos ellos pertenecían a los sectores más favorecidos. Como se mencionó, el concepto de una zona de amortiguamiento es un importante componente de la zonificación del Distrito Federal, ya que su objetivo es contener la expansión física de la ciudad. Dado que esta zona está bien especificada en el PDDF y en el plan parcial de la delegación, parece contradictorio que la gente supiera más acerca del PDDF, y no tuviera casi conocimiento de la existencia de la zona de amortiguamiento, especialmente viviendo dentro

CUADRO 4

Población que no tenía conocimiento de la existencia del PDDF, por nivel de ingreso y zonas (\%)

\begin{tabular}{lcccc}
\hline & \multicolumn{5}{c}{ Niveles de ingreso } \\
\cline { 2 - 5 } Zonas & Bajo & Medio & \multicolumn{1}{c}{ Alto } & Media \\
\hline Área urbana & $76.74(33)^{\star}$ & $\mathbf{3 8 . 8 9 ( 1 4 )}$ & $\mathbf{2 5 . 0}(3)$ & $\mathbf{5 5 . 0}(50)$ \\
Zona de amortiguamiento & $75.77(147)$ & $\mathbf{5 4 . 8 4 ( 1 7 )}$ & $\mathbf{4 3 . 4 0 ( 2 3 )}$ & $\mathbf{6 7 . 2 ( 1 8 7 )}$ \\
Todos los asentamientos & $\mathbf{7 6 . 0 ( 1 8 0 )}$ & $\mathbf{4 6 . 2 7 ( 3 1 )}$ & $\mathbf{4 0 . 0}(26)$ & $\mathbf{6 4 . 2 ( 2 3 7 )}$
\end{tabular}

* Los números en paréntesIs indican números absolutos.

Fuente: encuesta socIoeconómica. 
de sus límites. Sin embargo, esto puede no ser necesariamente verdadero, si se considera que el propio concepto de zona de amortiguamiento es sumamente "técnico" en términos de planeación, necesitándose una visión integral de los problemas de expansión urbana para entender totalmente su objetivo. También, y quizá de manera crucial, el concepto de zona de amortiguamiento no está relacionado en la práctica con ningún programa particular de dotación de servicios, regularización de tenencia de tierra, vivienda, etc., sino que es simplemente una norma de planeación que pretende contener la expansión urbana. Los planes parciales de desarrollo urbano como el de la delegación de Tlalpan junto con normas de planeación (por ejemplo la zona de amortiguamiento), no se vincularon a proyectos urbanos particulares para mejorar las condiciones de vida locales. La falta de acciones inmediatas para mejorar las necesidades básicas relacionadas a tierra, vivienda o servicios ofrecieron aparentemente poca motivación a la gente para informarse acerca de los instrumentos de planeación. Mientras menos es afectada la gente por los planes y las normas, menos conocimiento existe acerca de estos instrumentos.

Nivel de participación comunal. Aquí se examina el grado al cual bajos niveles de conocimiento pudieran reflejar una participación limitada en los comités de manzana. Según los resultados de la encuesta, aproximadamente $50 \%$ de la muestra respondió que participaba en un grupo o asociación local de residentes con el fin de demandar la introducción de servicios públicos o regularización de la tierra. En términos generales, esto confirma la afirmación hecha por Nelson (1979: 305) en el sentido de que los esfuerzos comunales de participantes activos para influir en las autoridades, tienden a no ser masivos. Otros datos de estudios acerca de la ciudad de México indican que menos de dos terceras partes de los residentes han participado en una actividad encaminada a resolver un problema comunal (Cornelius, 1975: 84), mientras que otros autores muestran que en esta misma ciudad $40 \%$ no se ha visto involucrado en demandas comunales (Gilbert y Ward, 1985: 206) ${ }^{18}$ En términos relativos se podrá afirmar que este porcentaje de participación es alto, puesto que difícilmente puede esperarse que todos y cada uno de los ciudadanos, en un momento dado, sean partícipes activos en demandas contra el gobierno de la ciudad.

Un aspecto importante de la participación es saber si los comités de manzana constituyen el principal medio para dicha participación. Únicamente $30 \%$ de la muestra total respondió que estaba involucrado en los comités de manzana, mientras que $21 \%$ participaba en otra organización comunal, fuera de los comités. Esto parece indicar que los comités de

${ }^{18}$ Esto apoya los hallazgos de Fisher (1977), que indican que en 16 de 19 barrios en Brasil, Chile, México, Perú y Venezuela, sólo de 20 a 40 por ciento de los residentes han tomado parte en alguna forma de demanda comunal (citado por Nelson, 1979: 305). 
manzana estaban fallando en atraer a residentes locales para participar en asuntos comunales, ya que aparentemente dos terceras partes de los residentes (205 de un total de 346) no estaban involucrados en estos canales institucionales. También queda claro que los comités no son los únicos medios de participación popular. Otras organizaciones compiten con los comités, lo que sugiere que algunas veces existen divisiones en las comunidades, por las cuales dos o más canales de participación están presentes en un asentamiento.

En términos generales, los comités de manzana fueron establecidos en la mayoría de los asentamientos encuestados. Sólo cinco de los 15 asentamientos no tenían comités, ya porque eran muy pequeños o porque tenían muy poca población residente. En áreas de baja densidad, donde manzanas completas incluían sólo dos o tres casas y múltiples lotes baldíos, era prácticamente imposible que los comités funcionaran. Esto también ocurría en las zonas de baja densidad de los asentamientos más grandes; así, las áreas residenciales de clases medias localizadas a lo largo de la carretera México-Cuernavaca fueron las áreas más grandes que carecían de esta representación. Aparentemente, donde los comités existían los residentes los usaban, aunque en un nivel limitado.

Sin embargo, si la existencia de los comités no garantizaba la participación de los residentes locales, éstos también estaban insatisfechos con el funcionamiento y establecimiento de dichos comités. Los habitantes encuestados en por lo menos cuatro asentamientos expresaron que los jefes de manzana no habían sido electos localmente y que su papel no era significativo para la comunidad. Los residentes sostenían que los jefes de manzana habían sido nombrados por la junta de vecinos de la delegación de Tlalpan y no por la comunidad local y, como un residente lo expresó, "eran sólo decorativos". Peor aún, algunos jefes de manzana admitieron que estaban decepcionados con su puesto de representantes al haberse dado cuenta que las autoridades locales en la delegación de Tlalpan no se interesaban en sus problemas y que habían hecho muy poco para satisfacer sus demandas. ${ }^{19}$ Era notorio que este tipo de argumentos estaba provocando, al menos en estos asentamientos, una falta de participación en los comités de manzana.

En la mitad de los asentamientos donde existía alguna forma de participación comunal, la presencia de otras organizaciones locales fue confirmada por los residentes y jefes de manzana. En dos colonias, el PRI tenía un papel muy activo; en una, su comité seccional era el que desempeñaba una función preponderante en la organización comunal, al grado que el líder local aceptaba que los representantes del PRI también eran los jefes

\footnotetext{
${ }^{19}$ Esta información fue obtenida de residentes y jefes de manzana en las colonias Héroes de Padierna, Ampliación Tepechimilpa, Tlalmille-Mirador del Valle, Los Encinos y José Lopez Portillo.
} 
de manzana; en la otra, la Asociación de Residentes de la República Mexicana (afiliada a la CNOP) organizaba todo lo relacionado con los problemas comunales, desde venta de lotes hasta tenencia de tierra. Otros dos asentamientos eran zonas urbano-ejidales (aún con carácter ilegal) y el comisariado ejidal de ambas era el más importante representante local. En otro asentamiento los residentes habian constituido una asociación civil para resolver todos los problemas comunales; en otro asentamiento más, el líder local (quien había sido el principal actor en la venta de lotes durante la etapa de formación de la colonia), aún mantenía la principal posición de poder y competía por apoyo, muy exitosamente, con los jefes de manzana. ${ }^{20}$ Dos asentamientos adicionales también tenían asociaciones civiles y participaban con la organización independiente Conamup. ${ }^{21} \mathrm{En}$ la mayoría de todos estos asentamientos, los niveles de participación en organizaciones populares alternativas era mayor que en los comités de manzana.

De esta manera, los datos presentados indican que los canales institucionales de participación popular están fallando en involucrar a toda la población que participa. La mitad de la población encuestada no participa en ninguna organización comunal, lo cual contribuye a debilitar los comités de manzana. La importancia de éstos decrece aún más debido a razones como su ausencia en algunas áreas residenciales, las irregularidades en su establecimiento y funcionamiento y la presencia de organizaciones alternativas de participación popular.

\section{Conclusiones}

Se ha señalado cómo el Estado mexicano promovió a finales de los años setenta un sistema de planeación urbana a nivel nacional y lócal, a través de instituciones para la planeación y un gran número de ambiciosos planes. Sin embargo, he buscado demostrar que el Estado mostró una falta de determinación para establecer mecanismos específicos y operativos para lograr los objetivos de dichos planes. A pesar de que las diferentes regulaciones de planeación incluían afirmaciones en el sentido de mejorar las condiciones de vida de los ciudadanos e involucrarlos en la toma de decisiones local, el esquema de planeación no atacó directa y clara-

${ }^{20}$ El PRi tenía una participación muy activa en Santa Úrsula Xitla a través de su Comité Seccional y además en la Tercera Sección del Mirador afiliada a la CNOP. Las zonas urbanoejidales eran Ejido de San Andrés Totoltepec y Cuchilla de San Andrés. Una asociación civil existía en Lomas Hidalgo y en Los Encinos; el líder local aún mantenía una fuerte influencia en la comunidad.

${ }^{21}$ Estos asentamientos eran Belvedere y 2 de Octubre. Aquí los residentes eran políticamente muy activos en declaraciones, marchas y demandas directas a la delegación de Tlalpan o al DDF. Una valiosa información fue obtenida por el autor de los líderes locales y de las juntas semanales de residentes. 
mente las causas sociales y económicas para mejorar los niveles de vida de los grupos más pobres. En este sentido, la planeación mostró una gran inconsistencia entre sus pronunciamientos (en su mayoría muy optimistas) y los medios concretos por los cuales tales fines podían llevarse a cabo; esto nos puede llevar a afirmar que se crearon expectativas falsas de la posible función de la planeación, y por lo mismo, podría pensarse que ésta fue usada o sirvió como fachada política de programas inexistentes o deficientes de alivio a la pobreza urbana y a la desigualdad social.

Sin embargo, no sería totalmente válido afirmar que las instancias analíticas aquí presentadas para el caso de Tlalpan (zona de amortiguamiento y participación popular), son representativas de toda la acción del Estado en el campo de la planeación urbana. Se harían necesarios otros análisis empíricos para constatar en qué medida los instrumentos de planeación no han sido observados. Pero al menos en este estudio podemos concluir que el proceso de planeación urbana a nivel nacional y local tuvo un alto contenido retórico que quizá podría interpretarse como respuesta política a un cierto descontento social motivado por la problemática urbana. Los controles de la planeación fueron laxos o muy limitativos y la acción del Estado fue a su vez tolerante cuando se exigía un control riguroso. Aquí podría argumentarse que la acción estatal dentro del campo de la planeación urbana puede ser complejamente discrecional: en ocasiones se controla rigurosamente (algo que quedaría por demostrar) y en otras hay laxitud y excepción. La búsqueda de respuestas a esta contradicción permitiría caracterizar la política urbana del Estado.

En nuestro análisis hemos visto que a nivel local las normas de planeación fueron débiles e irrelevantes para controlar la expansión física. Estas regulaciones mostraron estar totalmente desvinculadas con la manera en que se apropia la tierra urbana, especialmente en el caso de ocupaciones ilegales de tierra. La planeación urbana no incluía ninguna estipulación para regular el mercado de la tierra ni estaba asociada con programas concretos para necesidades y problemas prioritarios tales como vivienda, empleo o dotación de servicios. El esquema adoptado para estimular la participación en la ciudad de México representó mecanismos muy limitados de consulta: se enfatizó el flujo de información hacia los ciudadanos y el deseo de una consulta popular sin dar ningún poder al público en el proceso de toma de decisiones. En la medida en que la planeación careció de medios específicos, prácticos y viables para lograr sus propuestas, son mayores los motivos para asociar su objetivo a un simple ejercicio retórico por parte del Estado, encaminado a mostrar no una genuina preocupación por poner en práctica la planeación sino sólo una imagen más moderna y tecnocrática. 


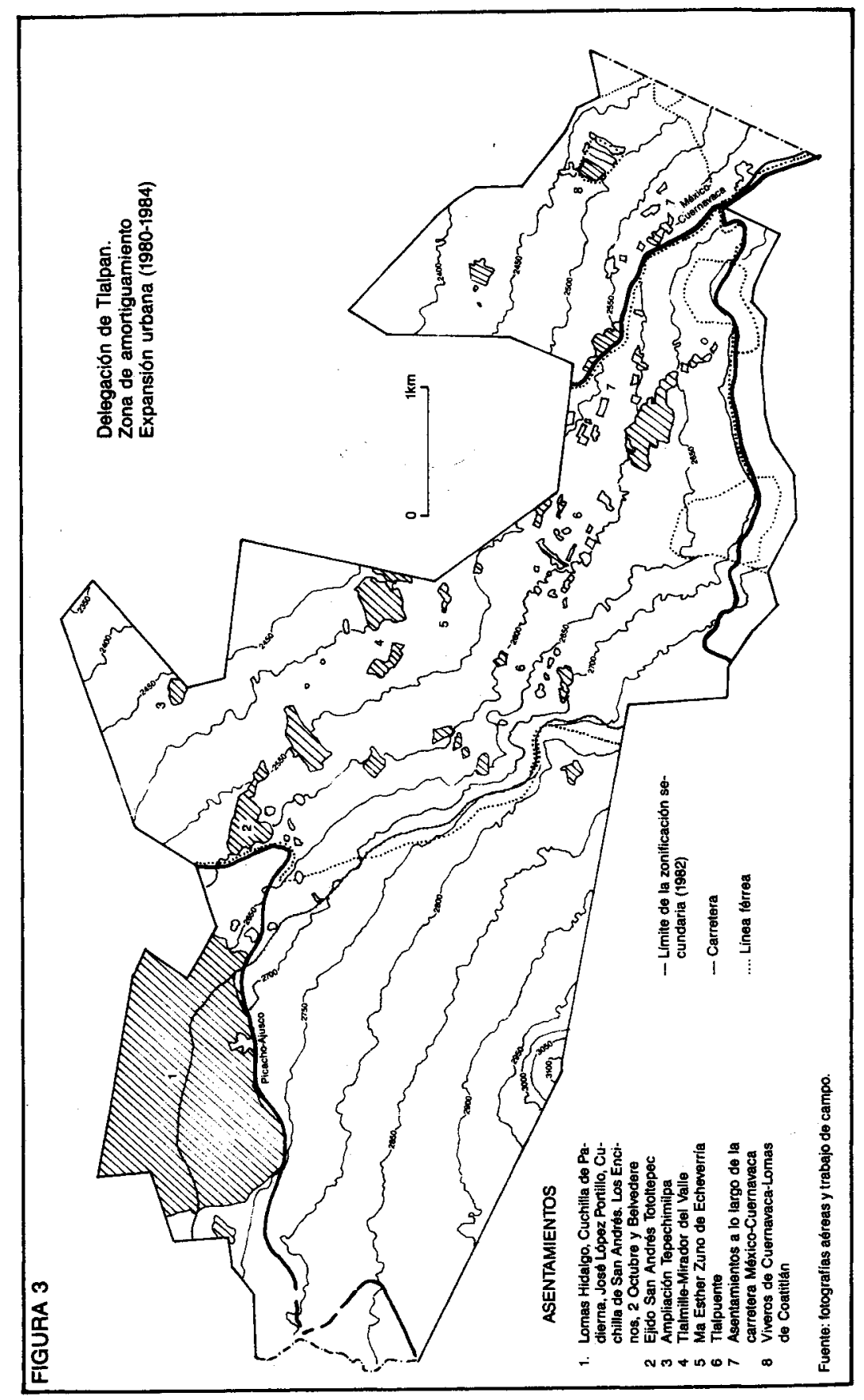




\section{Bibliografía}

Aguilar, A.G. (1986), Contemporary Urban Planning in Mexico City: Its Emergence, Role and Significance, tesis doctoral inédita, University of London, Londres.

Bahra, A. (1967), Crecimiento económico de América Latina. Problemas fundamentales, Editorial del Pacífico, Santiago de Chile.

Blanco, J. (1981), "El desarrollo de la crisis en México, 1970-1976", en Cordera, R. (ed.) Desarrollo y crisis de la economía mexicana, Fondo de Cultura Económica, México.

Bromley, R.J. (1977), Development and Planning in Ecuador, Latin American Publications Fund, Londres.

Castells, M. (1977), "Apuntes para un análisis de clase de la política urbana del Estado mexicano", en Revista Mexicana de Sociología, vol. xxxix, núm. 4.

Cibotti, R. y otros (1974), "Evolución y perspectivas de los procesos de la planificación en América Latina", en ILPES, OEA, BID, Experiencias y problemas de la planificación en América Latina, Siglo XXI, México.

Cisneros Sosa, A. (1983), "Los ciudadanos del Distrito Federal", en Revista de Ciencias Sociales y Humanidades, 9 .

Cornelius, W. (1975), Politics and the Migrant Poor in Mexico City, Stanford University Press.

Cornelius, W. y R. Kemper (eds.) (1978), Metropolitan Latin America: The Challenge and the Response, Latin American Urban Research, vol. 6, Sage Publications, California.

DDF (1980), Plan de Desarrollo Urbano, Plan General del Plan Director, versión abreviada, DDF, México.

DDF (1982), Sistema de Planificación Urbana del Distrito Federal, DDF, México.

De Mattos, C.A. (1979), "Plan Versus Planning in Latin American Experience", en CEPAL Review, núm. 8, agosto de 1979.

Diario Oficial (29-12-70), "Ley Orgánica del Departamento del Distrito Federal".

Diario Oficial (26-5-76), "Ley General de Asentamientos Humanos".

Diario Oficial (14-12-76), "Reglamento de Construcciones para el Distrito Federal".

Diario Oficial (7-1-76), "Ley de Desarrollo Urbano del Distrito Federal".

Diario Oficial (29-12-78), "Ley Orgánica del Departamento del Distrito Federal".

Fisher, ). (1977), Political Learning in the Latin American Barriadas: The Role of the Juntas de Vecinos, tesis doctoral inédita, John Hopkins University.

Garza, G. y M. Schteingart (1978), "Mexico City: The Emerging Megalopolis", en Cornelius, W.A. y R. Kemper (eds.), Metropolitan Latin America: The Challenge and the Response, Latin American Urban Research 6, Sage Publications, California.

Garza, G. (1986), "Planeación urbana en México en periodo de crisis (1983-1984), en Estudios Demográficos y Urbanos, vol. 1, núm. 1.

Gilbert, A. y P. Ward (1985), Housing, the State and the Poor, Cambridge University Press.

González Casanova, P. y E. Florescano (coords.) (1979), México hoy, Siglo XXI, México. ILPEs (1966), Discusiones sobre planificación, Siglo XXI, México.

McAuslan, P. (1985), Urban Land and Shelter for the Poor, Earthscan.

Nelson, J.M. (1979), Access to Power. Politics and the Urban Poor in Developing Nations, Princeton University Press.

Ramírez Sáiz, J.M. (1983), Carácter y contradicciones de la Ley General de Asentamientos Humanos, Instituto de Investigaciones Sociales, UNAM, México.

Rébora, A. (1978), "El ordenamiento territorial y urbano en México. Problemas y perspectivas", en Comercio Exterior, vol. 28, núm. 10, pp. 1181-1191.

Riffka, S. e I. Fernández (1981), "El desarrollo regional y el cambio sociopolítico en 
América Latina", en Boisier, S. y otros (comps.), Experiencias de planificación regional en América Latina. Una teoría en busca de una práctica, CEPAL, ILPES, sIAP, Santiago de Chile.

Schteingart, M. (1983), "La incorporación de la tierra rural de propiedad social a la lógica capitalista del desarrollo urbano: el caso de México", en SIAP, Relación campo-ciudad: la tierra, recurso estratégico para el desarrollo y la transformación social, Sociedad Interamericana de Planificación, México.

(1984), "EI sector inmobiliario y la vivienda en la crisis", en Comercio Exterior, vol. 34, núm. 8.

Unikel, L. y A. Lavell (1979), "El problema urbano en México", El Colegio de México, México, mimeo.

UnomásUno (8-9-81).

Varley, A. (1985), Ya somos dueños: Ejido Land Development and Regularization in Mexico City, tesis doctomal inédita, University of London, Londres.

Ward, P.M. (1981), "Political Pressure for Urban Services: The Response of Two Mexico City Administrations", en Development and Change, 12, 379-407.

Wynia, W.G. (1972), Politics and Planners: Economic Development Policy in Central America, The University of Wisconsin Press. 
, 